\title{
Psiquiatría y literatura en la España de la transición: los renglones torcidos de Dios (1979)*1
}

\author{
Rafael Huertas*2
}

\begin{abstract}
El objetivo de este trabajo es analizar los contenidos psiquiátricos de la novela de Torcuato Luca de Tena Los renglones torcidos de Dios (1979), con el fin de valorar de qué manera esta obra de ficción fue capaz de reflejar la realidad asistencial en la España de los años setenta en un contexto de profundos cambios culturales en torno a la locura. La novela refleja una posición conservadora de resistencia y critica a las novedades (el psicoanálisis, el movimiento antipsiquiátrico) que estaban propiciando un cambio de la "cultura psi” en la España de la Transición democrática.
\end{abstract}

Palabras clave: Torcuato Luca de Tena, psiquiatría, antipsiquiatría, manicomio, Transición democrática

${ }^{* 1}$ Este artículo tiene su origen en una ponencia presentada en el VI Encuentro de la Red Iberoamericana de Historia de La Psiquiatría celebrado em Santiago de Chile los dias 1-3 de diciembre de 2016.

*2 Centro de Ciencias Humanas y Sociales. Consejo Superior de Investigaciones Científicas (Madrid, España). 
HISTÓRIA DA PSIQUIATRIA

Introducción

La publicación en 1979 de Los renglones torcidos de Dios, de Torcuato Luca de Tena (1923-1999), supuso un innegable éxito de público y crítica que se ha repetido en sucesivas ediciones hasta llegar a ser considerada como "una de las obras más emblemáticas de nuestra literatura contemporánea, destinada a convertirse en un clásico", según se asegura en la edición conmemorativa del treinta aniversario, publicada por Planeta en 2009. La novela cuenta con una versión cinematográfica, del mismo título, producida en México y dirigida por el argentino Tulio Demicheli en 1983 e, incluso, ha llegado a inspirar un tema del grupo español de folk-heavy Mago de Oz.

Los renglones torcidos de Dios aborda un tema singular. $\mathrm{Su}$ protagonista, una mujer culta y muy inteligente llamada Alice Gould (o Alicia de Almenara), es ingresada en un manicomio. En su delirio cree ser una detective privada que, haciéndose pasar por una paciente, permanecerá varios días en la institución para esclarecer un caso de asesinato. Según una carta de su médico particular, dirigida al director del establecimiento, Alicia padece un cuadro paranoico y ha intentado envenenar a su marido. Su acusada personalidad, perspicacia y habilidades sociales confunden a los médicos hasta el punto de hacerles dudar si la mujer ha sido víctima de un ingreso arbitrario o si realmente padece un trastorno metal. Esta reflexión sobre los límites entre la locura y la cordura es el hilo conductor de la novela y, probablemente, una de las razones fundamentales de su éxito, pues el lector entra con facilidad en la trama y comparte los dilemas de los facultativos. Asimismo, y más allá de la mera digresión sobre el estado mental del personaje principal, la novela describe el espacio físico, el ambiente y la vida cotidiana en el interior del manicomio. Para conseguir este 
objetivo, Luca de Tena hubo de documentarse sobre el funcionamiento de las instituciones mentales en un momento tan concreto y significativo como la década de los setenta. Una época en la que, además de las importantes transformaciones políticas y sociales que se estaban produciendo en el estado español - el final del franquismo y los primeros años de la Transición democrática -, iba cristalizando un cambio cultural hacia el problema de los trastornos mentales que dio lugar a reformas asistenciales y novedades muy importantes en torno al discurso y a la actitud social hacia la locura, pero también debates y puntos de vista encontrados sobre la esencia de la enfermedad mental y sobre su tratamiento.

La novela de Luca de Tena se convierte así en una fuente de interés para apreciar el impacto de esa nueva "cultura psiquiátrica" en España, al menos desde posiciones conservadoras, y profundamente afines al orden establecido, como las que este autor representa. Torcuato Luca de Tena, nieto del fundador del $A B C$ y director de dicho periódico en 1952 y 1953 y entre 1962 y 1975 , fue un monárquico legitimista que, si bien mantuvo cierta distancia con Franco debido al debate sucesorio, siempre aceptó y colaboró con la Dictadura llegando a ser Procurador en Cortes en 1964 (Luca de Tena, 1993).

144 Además de su actividad periodística, su faceta como novelista, ensayista y dramaturgo le valió un sillón en la Real Academia de la Lengua en 1973 (Rodríguez Puértolas, 2008, pp. 732-733).

Luca de Tena ya había abordado el tema del trastorno mental en su novela Pepa Niebla (1965), pero en esta ocasión su abordaje es más abarcador; la locura es en sí misma el tema central, el escenario en el que se desarrolla la acción es un manicomio y los personajes son los pacientes y los encargados de su custodia. Mi propósito en las páginas que siguen es analizar los contenidos psiquiátricos de Los renglones torcidos de Dios, con el fin de valorar de qué manera esta obra de ficción fue capaz de reflejar la realidad manicomial en la España de los años setenta, sus limitaciones y sus aciertos, en el señalado contexto de profundos cambios culturales en torno a la locura.

Un periodista en el manicomio

El interés de los periodistas por informar a la opinión pública de lo que sucede detrás de los muros de un manicomio tiene una larga tradición. Son pioneros, en este sentido, los artículos de Nellie Bly, considerada una de las precursoras del periodismo de investigación (Kroeger, 1994), en The New 


\section{HISTÓRIA DA PSIQUIATRIA}

York World. Tras hacerse pasar por una enferma mental, y estar ingresada durante diez días en el manicomio de la isla de Blackwell (The Blackwell's island Asylum), denunció las condiciones de vida y el maltrato al que eran sometidos los pacientes mentales (Bly, 1887).

En España, cabe recordar el reportaje que Jacinto Toryho realizó sobre el manicomio de Ciempozuelos (próximo a Madrid), publicado en el periódico anarquista Solidaridad Obrera en 1933 (Rey y Martí Boscá, 2008) y, ya durante la dictadura franquista, la serie de artículos que el periodista y novelista Ángel María de Lera (1971) publicó en Tribuna Médica, y que posteriormente se agruparon en Mi viaje alrededor de la locura, o la colaboración de Guillermo Díaz-Plaja (1971) en la revista Triunfo. Relatos que, con mayor o menor contundencia, denuncian las penosas condiciones de vida de las personas internadas en los establecimientos psiquiátricos, la brutalidad coercitiva de los tratamientos o las escasas posibilidades de curación e integración social de los pacientes. Todo lo cual refleja, en muy buena medida, la preocupación de al menos una parte de la opinión pública por la reforma de las instituciones (no solo las psiquiátricas) en los años del tardofranquismo.

Aunque Los renglones torcidos de Dios sea una novela, Luca de Tena no renuncia a su condición de periodista. Su esfuerzo por documentarse y obtener la información necesaria para elaborar una narrativa suficientemente realista se encaminó, por un lado, a consultar con especialistas, como Juan Antonio Vallejo-Nágera, que escribe un prólogo al que más tarde nos referiremos, y por otro, a conocer de primera mano cómo era la vida de los pacientes mentales en el interior de un manicomio. Con este último fin, Luca de Tena se las arregló para ingresar y permanecer durante diez y ocho días en el manicomio de Conxo (municipio de Santiago de Compostela) simulando una psicosis depresiva. Su propósito, según se indica en una nota explicativa previa que aparece en todas las ediciones de la novela, no era otro que "mejor conocer, desde dentro, la pavorosa realidad que pretendía describir" (Luca de Tena, 1979/2005, p. 6). El Hospital Psiquiátrico de Nuestra Señora de la Fuentecilla, instalado en una antigua cartuja próxima a Zamora, es la institución imaginaria en la que se desarrolla la acción pero está, en gran parte, inspirado en el citado manicomio de Conxo, habilitado en un antiguo monasterio, del mismo modo que los personajes (personal sanitario, pacientes, familiares) están "copiados de la realidad" aunque sus historias sean inventadas. Un tipo, pues, de novela pretendidamente realista que debe mucho a la vocación periodística de su autor. 


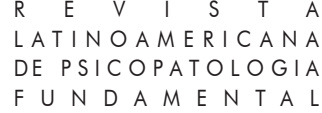

Veamos a continuación de qué manera Luca de Tena plasma, a través de la peripecia de su protagonista, su visión de la locura y del funcionamiento de las instituciones psiquiátricas.

\section{Ingresando en el psiquiátrico}

Como ya se ha adelantado, la novela comienza con el ingreso de Alicia en el Hospital Psiquiátrico. Es muy interesante la repetida alusión a la legislación que regulaba los ingresos y altas en los establecimientos psiquiátricos: el decreto de 3 de julio de 1931, aprobado durante el primer bienio republicano, que permaneció vigente durante todo el franquismo y la Transición y que no se derogó hasta el año 1983 (Huertas, 2016). Un decreto que, en su origen, hay que entender en el marco de los significativos cambios que en materia de política sanitaria se produjeron en la Segunda República (Huertas, 2000) pero que acabó consagrando el poder médico no solo sobre los pacientes, sino también sobre los administradores y los juristas. Las consideraciones médicas primaron sobre las que pudieran emanar del derecho civil, de modo que el riesgo de anular las garantías jurídicas de los pacientes en cuanto a privación de su libertad fue una consecuencia directa del nuevo decreto (Comelles, 1988, p. 140). En definitiva, el decreto otorgaba un cheque en blanco a una práctica asistencial que encerraba, en sí misma, un gran riesgo autoritario (Barrios, 2012). Esta circunstancia fue criticada en pleno franquismo desde las cátedras de Derecho Civil, lamentando la falta del control judicial a favor del gubernativo o administrativo y, naturalmente, del poder médico. Así, por ejemplo, en 1951, se argumentaba que "Las detalladas disposiciones del Decreto de 1931, a causa quizá de haberse tenido presente sólo consideraciones médicas y, a lo más, administrativas, olvidándose de los preceptos jurídicos sustantivos, hacen nacer graves dudas sobre su legalidad" (De Castro, 1951, p. 286). Críticas que serán retomadas, en términos muy similares, en el indicio de la Transición democrática (Bercovitz, 1976).

Luca de Tena demuestra tener un amplio conocimiento tanto de la normativa vigente sobre ingresos y altas, como de las críticas suscitadas. La protagonista asegura insistentemente que está "legalmente secuestrada" (Luca de Tena, 1979/2005, pp. 23, 24, 27), debido a una "defectuosa legislación respecto a la reclusión de enfermos en los sanatorios psiquiátricos" ( $\mathrm{p}$. 27), ofreciendo incluso detalles de su situación que corroboran el peso de las decisiones médicas frente a las judiciales: "No estoy aquí por 


\section{HISTÓRIA DA PSIQUIATRIA}

sentencia judicial. Fui acusada (...) no ante un tribunal sino ante un médico incompetente" (p. 24). Un médico que, engañado o convencido por el marido de la protagonista, firmó un informe en el que se especificaba, como ya se ha dicho, que ésta presentaba un síndrome paranoico y había atentado contra la vida de su cónyuge. Al margen de que en la trama de la novela no termine de quedar claro si tal informe clínico fue o no producto de una conspiración contra Alicia, no cabe duda que el engranaje burocrático-administrativo previsto se puso en marcha con toda precisión.

La salida de la institución dependía también de un criterio exclusivamente médico. El interno podía ser dado de alta por el facultativo, pero si era el propio paciente el que la solicitaba, el artículo 11 del decreto señalaba que el director médico podía oponerse si consideraba que el sujeto presentaba "signos de pérdida de la libre determinación de su voluntad y de la autocrítica de su estado morboso, o manifestaciones de peligrosidad" (Gaceta de Madrid, 1931).

Cuando Alicia pregunta al médico que la atiende en el hospital: “¿Cuáles son los trámites legales para salir del manicomio?", este le responde:

En tu caso, Alicia, o por solicitud formal de tu marido al director del hospital (que puede ser denegada por este caso de considerarse un estado de peligrosidad) o cuando Samuel Alvar [el director del manicomio] por sí mismo considere que no tienes razón alguna para seguir internada, en cuyo caso serías devuelta a tu marido, aunque este no te reclamase. De aquí que me parezca una torpeza por tu parte crearte un enemigo iprecisamente en el director! (Luca de Tena, 1979/2005, p. 306)

Vemos, pues, de qué manera Luca de Tena describe con gran precisión los trámites burocráticos-administrativos de ingreso y alta en los establecimientos psiquiátricos, pero también cómo sus críticas están muy en consonancia con los reparos que ante los mismos se venían produciendo. Algo un poco distinto a lo que ocurre con la visión que se transmite de la enfermedad mental, en la que se alternan, como veremos a continuación, descripciones muy precisas con metáforas excesivas y estigmatizadoras.

\section{En torno a la locura}

Como ya se ha adelantado, el psiquiatra Juan Antonio Vallejo-Nágera Botas fue el prologuista de la novela que nos ocupa. Hijo del conocido 


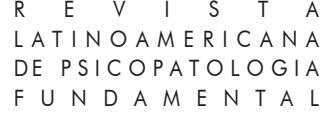

psiquiatra militar y catedrático de Psiquiatría Antonio Vallejo Nágera, cuya vinculación con el primer franquismo ha sido ampliamente estudiada (Huertas, 1998; Campos y Huertas, 2012), fue un célebre y polifacético médico y escritor que llegó a obtener el premio Planeta en 1985 (VallejoNájera, 1985). Divulgador, ensayista, conferenciante, pintor de estilo naif, encuadernador, etc., y célebre personaje de la jet set durante el segundo franquismo y la Transición, formaba parte de la misma élite ilustrada y conservadora a la que pertenecía Luca de Tena.

Una de las primeras ideas que dicho prólogo intenta trasmitir y elogiar es la habilidad "casi diabólica" del autor de Los renglones torcidos de Dios para "reinterpretar los síntomas, variando constantemente el diagnóstico según conviene a su relato, sin perder verosimilitud clínica" (Vallejo-Nájera, 1979/2005, p. 10). Solo al final de la obra se sabe si el diagnóstico de paranoia es adecuado al estado mental de la protagonista o si sus manifestaciones han sido simuladas. Las características clínicas de la paranoia se prestaban a este juego permanente, a este vaivén continuo de duda e incertidumbre sobre su estado mental.

En todo caso, no cabe duda que dichas características clínicas son descritas con bastante precisión. Así, ya desde el mismo momento del ingreso, el Dr. Ruipérez, anota: "fábula delirante perfectamente urdida y razonada. Conclusión provisional: paranoia pura" (Luca de Tena, 1979/2005, p. 27). Pero el diagnóstico de paranoia, al contrario que el de esquizofrenia, no es fácil de establecer:

Las esquizofrenias tienen de común con las paranoias la existencia de unos delirios de interpretación: la deformación de la realidad exterior por una tendencia invencible $\mathrm{y}$, por supuesto, morbosa, a ver las cosas como no son. Pero así como en las esquizofrenias tales transformaciones de la realidad son con frecuencia disparatadas, incomprensibles y radicalmente absurdas, en las paranoias, por el contrario, suelen estar tan teñidas de lógica que forman un conjunto armónico, perfectamente sistematizado, y tanto mejor defendido con razones, cuanto mayor es la inteligencia natural del enfermo. (p. 25)

Es cierto que el delirio paranoico es sistematizado, coherente, lógico y con claridad y orden de conciencia, pensamiento y conducta. En este sentido, Luca de Tena recoge con bastante claridad esta situación clínica: "Todos los paranoicos parecen muy normales" (p. 125), lo que le permite plantear la posibilidad de que Alicia se haga pasar por loca con relativa facilidad, al no 


\section{HISTÓRIA DA PSIQUIATRIA}

verse obligada a "simular la euforia del maniaco, ni la pavorosa tristeza del deprimido, ni la absurdidad del esquizofrénico, ni la idiocia del demente", pero al mismo tiempo recordar que su inteligencia y aparente sensatez son compatibles con el diagnóstico de paranoia, pues "cuantos padecen este mal son razonadores, muchos de ellos inteligentes y suelen cumplir a la perfección las obligaciones propias de sus oficios o profesiones. (...) los paranoicos no muestran más síndromes de anormalidad que los relacionados con su delirio particular" (p. 87).

Las llamadas locuras parciales - o las locuras razonantes - han sido, sin duda, uno de los grandes los caballos de batalla de la psiquiatría desde sus orígenes. Cuando Sérieux y Capgras (1909), describieron el delirio de interpretación, reconocieron su deuda con Esquirol (Huertas, 2008) $\mathrm{y}$, en particular, con sus monomanías intelectuales. Monomanía, delirio de interpretación y paranoia se sitúan en una misma línea de desarrollo conceptual atravesada por cambios en el entorno socio-cultural. En líneas generales, se trata de categorías en las que la "idea fija" es el elemento psicopatológico fundamental: el alienado conserva el uso de la razón y no delira más que sobre un objeto o círculo muy limitado de ideas, sintiendo, razonando y obrando en los demás órdenes de la vida como lo hacía antes de sufrir la enfermedad.

Luca de Tena recoge toda esta tradición construyendo un personaje con una (supuesta) patología muy difícil de diagnosticar porque se trata de una "loca que no lo parece" (Esquerdo, 1881; Huertas, 2003). Alicia es una mujer perfectamente sana salvo cuando intenta envenenar a su marido. Su delirio parcial - su idea fija - queda perfectamente acotada, pero no por ello deja de suscitar inquietud y desconfianza:

La consideró doblemente peligrosa - por su enfermedad y por su inteligencia - y se dispuso a tomar medidas severas para evitar que dispusiese de nada - en el vestuario, en sus enseres, incluso en sus objetos de tocador - con los que pudiese atentar contra su vida o contra la de los demás. (Luca de Tena, 1979/2005, pp. 28-29)

Sin embargo, a pesar de la habilidad con la que el autor juega con un diagnóstico verosímil y sobre el que se ha documentado ampliamente, la personalidad de su protagonista va mucho más allá de la mera patología. Se trata de una mujer que ejerce una gran fascinación sobre el resto de los enfermos ingresados pero también sobre el personal del hospital y, en particular, sobre el experimentado César Arellano, jefe clínico del 
establecimiento, que llega a definirla como "demasiado perfecta" (p. 424), de "ideales elevados", "pura", "delicada", "inteligente" (p. 425), con "personalidad superior. Espíritu exquisito. Altamente cultivada" (p. 200); toda una constelación de virtudes que hace que "Alice Gould no solo ha cautivado con su bondad y su personalidad a usted y a mí. Todos los médicos de la junta son amigos suyos y harán lo indecible por favorecerla" (p. 417). Tan solo el director del manicomio, que aparece como el personaje negativo, el enemigo con el que se confronta constantemente, es el único que no duda nunca de su trastorno mental.

Incluso el narrador parece extasiado por su personaje, cuyos valores burgueses y conservadores - los del propio Luca de Tena - quedan patentes a lo largo de la obra. Su condición social parece protegerla: "esta señora - tan distinta en su porte y en su atuendo a los habituales pacientes - no parecía demandar amparo, sino exigir pleitesías" (p. 19). Un componente fuertemente clasista acorde con los valores que Alicia representa: superioridad intelectual y moral (de clase) que le permite manipular a todos los que se rinden ante su personalidad. Una personalidad que resulta en muchos momentos prepotente y pedante, incluso rayando una especie de narcisismo 150 histérico, pero que siempre es descrita como parte de un encanto especial y poderoso.

Por lo demás, los valores conservadores que Alicia/Luca de Tena encarnan se ven reflejados también en las alusiones a prácticas sexuales que considera inapropiadas, viciosas o patológicas: "Me ha dado mucha pena conocerle. Mucha. ¿Es homosexual?” (p. 170); “Es repugnante! ¿Cómo puede tolerarse que se practique el onanismo...? (p. 358); "Volvióse y observó a una reclusa realizando, enajenada, el vicio solitario" (p. 359). Expresiones cargadas de intención, por supuesto muy extendidas en la época, pero que se confrontan con los cambios culturales que en torno a la sexualidad estaban teniendo lugar a finales de los años setenta, desde el fenómeno del destape (Ponce, 2004; Cominges, 2001), hasta las primeras iniciativas de reivindicación de la homosexualidad y del cuestionamiento de su condición patológica (Mira, 2004, p. 415 y ss).

Otras muchas patología mentales (fobia, esquizofrenia, oligofrenia, depresión, delirios diversos, sífilis, alcoholismo, demencia,...) desfilan por las páginas de la novela con descripciones más someras que la paranoia de la protagonista. Pero lo que llama especialmente la atención son las abundantes metáforas empleadas para referirse a la locura en general y que nos ofrecen una visión cosificadora y estigmatizante de la misma. Sirva 


\section{HISTÓRIA DA PSIQUIATRIA}

como ejemplo, la consideración de los enfermos mentales como "individuos llagados en el espíritu, tarados del alma" (Luca de Tena, 1979/2005, p. 31), y del manicomio como un "museo de horrores, un álbum vivo de esperpentos" (p. 57), que alberga una "interesante colección de monstruos" (p. 30). Los pacientes mentales serían, en suma, "errores de la Naturaleza" o, lo que sería equivalente pero atravesado por un pensamiento católico, una "equivocación divina". A eso se alude desde el propio título de la novela y se insiste en su interior: "¡Ah, qué terrible es el sino de los pobres locos, esos 'renglones torcidos', esos yerros, esas faltas de ortografía del Creador...!" (p. 320). Ante tal desdicha solo queda caridad cristiana, afán de ayuda a estos desventurados, e intento de "enderezarlos" mediante la labor "heroica" de la psiquiatría.

Luca de Tena ofrece una visión de la psiquiatría muy positiva y esperanzadora y hasta dedica la novela a sus profesionales: “...a los médicos, a los enfermeros y enfermeras, a los vigilantes, cuidadores y demás profesionales que emplean sus vidas en el noble y esforzado servicio de los más desventurados errores de la naturaleza". Sin embargo, no oculta la existencia de distintas escuelas, y de los diversos enfoques teóricos y terapéuticos que se enfrentaban en la práctica psiquiátrica y que iban desde la psiquiatría biológica a la dinámica sin olvidar la psiquiatría social y el impacto del movimiento antipsiquiátrico.

\section{Pugna entre escuelas}

Luca de Tena da cuenta de los tratamientos biológicos más habituales en la práctica manicomial, con referencias explícitas al electroshock y al coma insulínico. En ambos casos se explica brevemente la técnica utilizada. Refiriéndose a la terapia electroconvulsiva, el médico explica a su paciente: "Haremos pasar por su cerebro una corriente eléctrica hasta de 130 voltios que sea capaz de provocar convulsiones, pérdida de conciencia y amnesia. (...) es precisamente lo que se pretende: el olvido del delirio" (p. 233). Con el choque insulínico lo que se pretende es

(...) llevarla al borde mismo de la muerte provocándole una hipoglucemia progresiva hasta que entre usted en coma. Cuando esté ya a las puertas de la agonía, la reviviremos suministrándole dosis masivas 


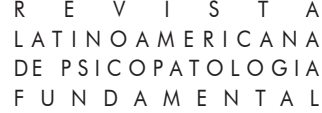

de glucosa. Y apenas esté usted repuesta repetiremos el tratamiento cuarenta o cincuenta veces (...) en tres o cuatro meses. (p. 233)

Mientras que el electroshock, cuyas primeras aplicaciones datan de los años cuarenta (Shorter y Healy, 2007), seguía siendo una técnica muy extendida en los setenta, llama la atención la alusión al choque insulínico porque, si bien formó parte del arsenal terapéutico de la psiquiatría desde los años treinta y fue profusamente utilizada durante los cuarenta, a partir del influyente artículo de Harold Bourne (1953), "The insulin myth", y con la introducción de los psicofármacos, su uso fue disminuyendo paulatinamente hasta desaparecer (Mitchell y Kirkby, 2014, p. 341). Un proceso perfectamente superponible a la realidad asistencial española (Conseglieri, 2008).

Resulta, en este sentido, un tanto anacrónico que Luca de Tena de a entender que su práctica era habitual en los establecimientos psiquiátricos, o que su prologuista asegure que "Tampoco los tratamientos con insulina conducen al 'borde de la muerte' al paciente, ni le dejan 'al borde de la agonía" (Luca de Tena, 1979/2005, p. 12), aun cuando esa sensación de muerte inminente de los pacientes tratados con este método está suficientemente documentada (James, 1992). Vallejo-Nájera no cuestiona la mencionada inexactitud cronológica y se limita a alejar a la psiquiátrica de toda sospecha, igual que cuando minimiza el escaso celo de los facultativos de la novela por mantener el secreto profesional o las posibles relaciones sentimentales entre médico y paciente. En todos estos casos se trataría de deformaciones deliberadas y admisibles en un escritor que "busca un refuerzo emocional" para su relato y "dar carga expresiva a esas escenas" (VallejoNájera, 1979/2005, p. 12). Licencias literarias que en ningún caso deberían cuestionar la ética profesional o deslegitimar las prácticas terapéuticas (aunque estas ya no se utilizaran) en un momento en el que, como ya hemos apuntado, la asistencia psiquiátrica generaba críticas y desconfianza en la opinión pública.

En cuanto a las referencias al psicoanálisis, estas resultan superficiales y un tanto manidas, pero su sola presencia resulta de interés si tenemos en cuenta su más que discreta presencia e institucionalización durante todo el franquismo (Carles, Muñoz y Llor, 2000). Para César Arellano, el competente jefe clínico del Nuestra Señora de la Fuentecilla, "Freud era un sabio que descubrió uno de los métodos más eficaces para hacer aflorar al consciente secretos morbosos, escondidos en nuestro interior (...) su error estriba en la 


\section{HISTÓRIA DA PSIQUIATRIA}

dirección unilateral que dio a sus interpretaciones" (Luca de Tena, 1979/2005, p. 68). La crítica al pansexualismo freudiano es muy evidente. Las primeras recepciones médicas del psicoanálisis en España están marcadas por la deslegitimación de la teoría freudiana al cuestionar el papel que ésta otorga a la sexualidad. El conflicto entre el discurso freudiano y la moral burguesa, católica y conservadora, que ha sido estudiado para épocas anteriores (Huertas y Novella, 2013), se mantiene en los personajes de Luca de Tena, unas veces con cierta cautela, como en el caso del dr. Arellano, quien pese a su admiración por el médico vienés, termina asegurando que estaba "equivocado en las interpretaciones exclusivamente sexuales que daba a los símbolos, los sueños y los secretos ocultos de nuestro subconsciente (p. 68); otras de manera mucho más vehemente, como cuando la propia Alicia exclama: “¡No solo somos sexo, doctor! ¡Odio a Freud!” (p. 68).

Sin embargo, a pesar de las evidentes reservas hacia la teoría freudiana, Luca de Tena incluye el psicoanálisis y la psicoterapia como prácticas relativamente frecuentes en la institución. Las entrevistas que el Dr. Arellano y su paciente Alicia mantienen tres o cuatro veces por semana tienen, sin duda, un fondo psicoterapéutico:

Eran especies de psicoanálisis de otro estilo a los habituales (...) El médico preguntaba, planteaba la cuestión y no intervenía más que para provocar a Alicia a hablar. No era tampoco extraño que fuera él quien tomara la palabra sobre temas muy concretos - sexuales, agresivos, milagros, visiones, alucinaciones - en cuyo caso hundía su mirada en ella para leer en su alma la reacción que producía. (p. 111)

Pero donde más claramente puede identificarse la práctica psicoanalítica es en el pasaje en el que el dr. Ruipérez trata una fobia: "¡Cuatro sesiones de psicoanálisis por semana, tumbado en el mismo diván, con la misma penumbra, el médico sentado tras de mí, siempre a la misma hora, en la misma posición, durante tres años!" (p. 154). Claro que tal grado de ortodoxia fracasó estrepitosamente: "El subconsciente no soltó prenda" (p. 154).

Como se ve, el psicoanálisis no termina de quedar demasiado bien parado aunque el autor maneja, no siempre con fortuna, cierta jerga especializada. Por ejemplo, la utilización repetida del término subconsciente, en vez de inconsciente, nos remite a una vieja discusión metodológica y semántica que, en cierto modo, denota la lejanía de Luca de Tena del psicoanálisis. Como es sabido, subconsciente es un término que utiliza la psicología "clásica" para designar todo aquello que está "por debajo" de la 
conciencia y que es débilmente consciente, mientras que inconsciente es un término propiamente psicoanalítico que se refiere de modo más preciso al contenido mental que se encuentra fuera del conocimiento de la persona, que permanece oculto, escapa de la conciencia y que está constituido por contenidos reprimidos (recuerdos, experiencias, sentimientos etc.).

En todo caso, esto no le impide poner en boca de sus personajes, expresiones como: la locura es la "sublimación patológica (...) de unas tendencias previas" (p. 157) o el psicoanálisis persigue la "afloración al consciente de las tendencias reprimidas en el subconsciente" (p. 158).

Hay que tener en cuenta que cuando la novela fue publicada ya habían empezado a llegar al estado español los psicoanalistas argentinos que, huyendo de la dictadura militar de su país (1976-1983), colaboraron de manera fundamental en la consolidación del psicoanálisis, creando escuelas y propiciando una práctica normalizada del mismo (Druet, 2012). Una novedad de calado, el de una mayor presencia del psicoanálisis en la sociedad y en la salud mental de la época, que Luca de Tena no podía ignorar.

Como tampoco obviar el revulsivo que para el discurso y las prácticas en torno a la locura supuso el movimiento antipsiquiátrico. Si César Arellano es descrito, como ya hemos visto, como un gran clínico, cuyos "diagnósticos y pronósticos tienen fama de infalibles" (Luca de Tena, 1979/2005, p. 91), Samuel Alvar aparece como un "magnífico organizador" que al llegar a la dirección del hospital inició una serie de reformas importantes. Como la enfermera Motserrat le explica a Alicia, intentando proscribir la palabra manicomio: "hoy los mani (...), los hospitales psiquiátricos, están mucho más humanizados. Nuestro actual director ha hecho una gran labor en este sentido" (p. 44). Además, Nuestra Señora de la Fuentecilla se presenta como una institución moderna, con talleres para laborterapia, supresión de rejas en las ventanas — "medida excelente para evitar la sensación de encierro opresivo" (p. 303) — y en la que se había inaugurado, con carácter pionero, el "régimen abierto" (p. 242), lo que significaba que

(...) los enfermos tenían derecho a moverse con relativa facilidad por el edificio o por el parque (...) la libertad se extendía hasta poder salir del sanatorio - y trasladarse en autobús a algún pueblo de las cercanías - lo que era muy solicitado (...) Esto era la norma general; pero las excepciones eran muchas también. (p. 90) 


\section{HISTÓRIA DA PSIQUIATRIA}

El buen Dr. Arellano reconoce la importancia de estas medidas y la buena intención del director:

(...) no debes ser injusta al juzgar a los antipsiquiatras. Su crítica de los antiguos sistemas hospitalarios ha sido muy constructiva y gracias a ellos se han hecho reformas admirables en los manicomios. Su fallo consiste en ser más "sociólogos" que "médicos", y en olvidar que para poner en práctica sus teorías primero hay que crear una infraestructura que las haga posibles. (p. 303)

Sin embargo, se apresura a enumerar sus inconvenientes: los pacientes pueden obtener herramientas en los talleres de laborterapia con las que agredir a algún semejante; la supresión de rejas en las ventanas aumentarían los suicidios y el régimen abierto multiplicarían las fugas (p. 254). Todo lo cual viene, en definitiva, a devaluar el valor de las reformas.

Samuel Alvar, el director del establecimiento, un psiquiatra "con mucho sentido social" (p. 95) es, en realidad, el villano de la historia. Es el único que no cae fascinado ante la personalidad encantadora de Alicia y es el que mantiene el diagnóstico de paranoia, mientras los demás dudan, e insiste en mantenerla ingresada. Además, es objeto de una gran conspiración dirigida por la propia Alicia, y en la que participa el personal facultativo y auxiliar del centro hospitalario, con el fin de que sea cesado o renuncie al puesto de director. $\mathrm{Y}$ ese enemigo a batir lo es, en buena medida, por ser un psiquiatra diferente: un "antipsiquiatra". Así es definido, a modo de insulto o de etiqueta infamante, cuando se indica que el desagrado que genera entre el resto del cuadro médico se debe precisamente a

(...) ser un antipsiquiatra. ¡Oh, doctor, le ruego que no se moleste si empleo ese término! Sé que a los de su secta, o su grupo, o su escuela, no les gusta que se les denomine así, pero todo el mundo lo hace y hay hasta libros escritos por antipsiquiatras que utilizan ese modo de decir. Se les acusa a ustedes de usar prácticas inusuales, de ser utópicos y de estar fuertemente politizados. (p. 253)

La antipsiquiatría, término propuesto por el psiquiatra británico David Cooper (1967), supone la cristalización de toda una línea de pensamiento alternativo a las teorías y prácticas psiquiátricas hegemónicas. El movimiento antipsiquiátrico, crítico y contracultural, puso en tela de juicio la psiquiatría tradicional y la propia noción de enfermedad mental (Crossley, 1998; Desviat, 2006). Su influencia en España durante la década de los setenta y los primeros ochenta no fue menor. Por un lado, los propios facultativos y 


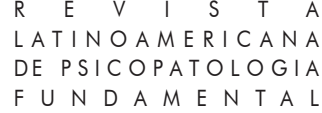

trabajadores psiquiátricos, al menos los más implicados en el cambio social y político, se organizaron propugnando cambios asistenciales y desarrollando movilizaciones y encierros en instituciones psiquiátricas de gran repercusión mediática y social (Comelles, 1986; Polo, 1999). La creación de la llamada Coordinadora psiquiátrica en 1971 desempeñó una labor de información, colaboración y coordinación entre profesionales que pretendió denunciar la penosa situación de la asistencia psiquiátrica en todo el país e impulsar reformas institucionales (Rendueles, 1997; González de Chávez, 2003).

Es interesante constatar que precisamente en el establecimiento psiquiátrico de Conxo, en el que Luca de Tena permaneció durante unos días con objeto de obtener información y experiencias para su novela, tuvo lugar a comienzos de los años setenta un intento de reforma asistencial que generó importantes conflictos. Al igual que en otros lugares, en Conxo se enfrentaban, según las declaraciones de un facultativo a un medio de la época, dos tesis opuestas, dos formas diferentes de entender la psiquiatría:

Una en la que el enfermo mental es un irresponsable al que hay que educar y al que hay que enseñar a adaptarse a las normas imperantes y otra en la que el enfermo mental simboliza y expresa las contradicciones de una sociedad dada en un tiempo y un lugar determinados (...) y somos todos, tanto los internos como los que prestamos nuestra asistencia, los que tenemos que liberarnos de esas contradicciones. (Quesada, 1975, p. 21)

Este primer intento reformador, basado en el modelo de comunidades terapéuticas y en una relación horizontal entre especialistas, personal sanitario y pacientes no pasó de ser una experiencia frustrada (González, 1977), pero no cabe duda que dejó una impronta que no pudo pasar desapercibida para un informado Luca de Tena, llegando a reflejar en su novela, como hemos visto, los enfrentamientos ideológicos y científicos entre profesionales y escuelas psiquiátricas.

\section{Conclusiones}

Como ya se ha indicado, la novela de Torcuato Luca de Tena, escrita y publicada durante los primeros años de la Transición democrática, se beneficia en parte de ese caldo de cultivo, de la fascinación del público lector por la locura y sus instituciones. 


\section{HISTÓRIA DA PSIQUIATRIA}

Sin embargo, a pesar de su temática manicomial, Los renglones torcidos de Dios no tiene nada que ver con otras novelas como One Flew Over the Cuckoo's Nest (1962) cuyo autor, Ken Kesey (1935-2001), se convirtió en una figura emblemática de la contracultura y del underground contestatario estadounidense (Bryfonski, 2010; Dodgson, 2013). Como es sabido, Milos Forman llevó al cine la novela de Kesey en 1975, obteniendo un notable reconocimiento (con cinco premios Oscar de la Academia de Hollywood) y un éxito popular que pudo haber influido en el interés, por parte del público español (el film se estrenó en España en octubre de 1976), de un producto literario, aparecido tres años más tarde, cuya acción se desarrollaba también en el interior de un hospital psiquiátrico. Pero aunque el concepto y la intervención sobre la locura están muy presentes en ambas obras, ahí termina cualquier similitud. Ni la actitud rebelde y transgresora de Randle McMurphy tiene parangón con la discreta resistencia de Alice Gould, ni mucho menos es comparable el destino final de ambos. Tampoco puede decirse que Luca de Tena pretendiera seguir la estela marcada por obras de un modo u otro relacionadas con la crítica antipsiquiátrica. Todo lo contrario.

En su doble faceta de periodista y novelista, Luca de Tena acomete la escritura de una novela que pretende ser fiel a la realidad, a la vez que entretener y agradar a un público amplio en su lógica búsqueda del éxito editorial y de mercado. Sin embargo, aunque la novela se convirtió en todo un best seller, no cabe duda de que se trata de un relato muy conservador que encierra en sí mismo un poso ideológico inmovilista y reaccionario ante las novedades, crisis y rupturas sociales y culturales que se estaban produciendo. Su crítica a los bienintencionados, pero utópicos y radicales, antipsiquiatras es muy evidente, pero mucha más importancia tiene, a mi juicio, la consideración de los enfermos mentales como errores de la Naturaleza, como renglones torcidos, lo que implica no solo un fuerte determinismo, sino también un discurso de exclusión y estigmatización de la locura. Es evidente que los medios de comunicación, pero también ciertas obras literarias, desempeñan un papel fundamental en el interés y la actitud de la opinión pública hacia las personas diagnosticadas de enfermedad mental (Byme, 2003). Algunos autores han insistido en las posibilidades que los medios pueden ofrecer para la reducción de la estigmatización de los trastornos mentales (Salter \& Byrne, 2000; Salter, 2003). En la España de la Transición la denuncia de las condiciones asistenciales y de vida de los pacientes en las instituciones hizo de periodistas y reporteros gráficos verdaderos agentes del 


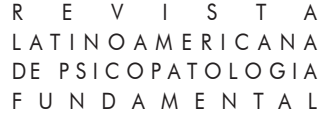

cambio social (Martínez Azumendi, 2005), lo que no es aplicable al periodista Luca de Tena cuando nos presenta, en una obra pretendidamente realista un hospital psiquiátrico, si no idílico, si al menos escasamente sospechoso de ser el espacio coercitivo, disciplinario y apenas terapéutico propio de las instituciones totales descritas por Goffman (1961), convertidas en dispositivos de poder psiquiátrico, en el sentido de Foucault (2003). Cabe señalar, a este respecto, la entusiasta aunque desigual recepción de la obra foucaultiana en determinados círculos de psiquiatras (Galán, 2009), que son, precisamente, los que en la novela se definen como sectarios y radicalizados.

Pero Los renglones torcidos de Dios no es un reportaje periodístico, por eso, aunque no hayamos podido ignorar la profesión de su autor, debemos analizar la obra como lo que es, como un relato de ficción. No cabe duda que la trama es inteligente, emotiva e interesante, y está sujeta a continuos giros que hacen dudar continuamente del estado mental de Alicia. Pero, además de la incertidumbre del diagnóstico, resulta muy interesante la manera en que se va produciendo de manera paulatina una implicación emocional de casi todo el personal psiquiátrico con la protagonista. Médicos y auxiliares terminan totalmente embaucados y manipulados por la inteligencia, la belleza y, en definitiva, la perfección de Alicia. La jactancia de una inteligencia superior ante las limitaciones de los profesionales resulta bastante efectista y reduce el supuesto realismo de la historia, pero introduce un elemento de reflexión no menos arrogante. Realmente, unos psiquiatras, con sus teorías, sus métodos y sus protocolos diagnósticos y terapéuticos, ¿son capaces de evaluar y tratar a una mente superior? ¿Puede la ciencia intervenir y ejercer control sobre una mente superior de una clase superior?

Tal vez Alicia de Almenara esté por encima del bien y del mal. Perteneciente a una élite social y cultural para la que todo está permitido y que se resiste a la remota posibilidad de perder sus privilegios. En el fondo no importa si Alicia ha intentado o no envenenar a su marido, y mucho menos que tenga un trastorno mental. Al final, todo se le perdona porque es superior, porque su clase y su inteligencia la protegen y la libran de esa otra locura, la de los otros, la que atenta contra el orden social establecido. Por eso, además de las posibilidades que la novela ofrece para analizar una narrativa sobre la locura con evidentes connotaciones ideológicas, y de confrontarla con otras maneras de entender el sufrimiento psíquico, Los renglones torcidos de Dios puede leerse también, y finalmente, como una gran metáfora en defensa de los valores pretendidamente inmutables que Alicia representa. 


\section{HISTÓRIA DA PSIQUIATRIA}

Agradecimientos: Este trabajo ha sido realizado en el marco del Proyecto de investigación "Psiquiatría y cambio social en España. 19601985" (HAR2015-66374-R) financiado por Ministerio de Economía y Competitividad (MINECO) de España y el Fondo Europeo de Desarrollo Regional (FEDER)

\section{Referencias}

Barrios, L. F. (2012). La regulación del internamiento psiquiátrico involuntario en España: carencias jurídicas históricas y actuales. Derecho y Salud, 22(1), 31-56.

Bercovitz, R. (1976). La marginación de los locos y el derecho. Barcelona: Taurus. Bly, N. (1887). Ten Days in a Mad-House. New York: Ian L. Munro.

Bourne, H. (1953). The insulin myth. Lancet, 265, 964-968.

Bryfonski, D. (2010). Mental Illness in Ken Kesey's One Flew Over the Cuckoo's Nest. Detroit: Greenhaven Press.

Byrne, P. (2003). Psychiatry and the media. Advances in Psychiatric Treatment, 9 , 135-143.

Campos, R., \& Huertas, R. (2012). Medicina mental y eugenesia: los fundamentos ideológicos de la psiquiatría franquista en la obra de Antonio Vallejo-Nágera. Historia del Presente, 20(2), 11-21.

Carles, F., Muñoz, I., Llor, C., \& Marset, P. (2000). Psicoanálisis en España (18931968). Madrid: Asociación Española de Neuropsiquiatría.

Comelles, J. M. (1986). La crisis de la psiquiatría española durante el Tardofranquismo y la transición. El caso del lnstitut Mental de la Santa Creu (1971-1986). Revista de la Asociación Española de Neuropsiquiatría, 6(19), 619-635.

Comelles, J. M. (1988). La razón y la sinrazón. Asistencia y desarrollo del Estado en la España contemporánea. Barcelona: PPU.

Cominges, J. (2001). Mis años de cine (1976-1979). Entre el destape y la "qualité". Barcelona: Dvd.

Conseglieri, A. (2008). La introducción de nuevas medidas terapéuticas: entre la laborterapia y el electroshock en el Manicomio de Santa Isabel. Frenia 8(1), 131-160.

Cooper, D. (1967). Psychiatry and Anti-Psychiatry. London: Tavistock.

Crossley, N. (1998). R. D. Laing and the british anti-psychiatry movement. A socio-historical analysis. Social Science and Medicine, 47(7), 877-889. 
De Castro, F. (1951). Derecho Civil de España. Tomo II. Derecho de la persona. Parte Primera. La persona y su estado civil. Madrid: Instituto de Estudios Políticos.

Desviat, M. (2006). La antipsiquiatría: crítica a la razón psiquiátrica. Norte de salud mental, 25, 8-14.

Díaz-Plaja, G. L. (1971). La asistencia psiquiátrica en España (I). Triunfo, 454, 11-15.

Díaz-Plaja, G. L. (1971). La asistencia psiquiátrica en España (y II): Institución, represión, contradicción. Triunfo, 455, 34-37.

Dodgson, R. (2013). It's All Kind of Magic: The Young Ken Kesey. Madison, WI: University of Wisconsin Press.

Druet, A. C. (2012). The transatlantic element: Psychoanalysis, exile, circulation of ideas and institutionalization between Spain and Argentina. Psychoanalysis and History, 14(2), 237-251.

Esquerdo, J. M. (1881). Locos que no lo parecen. Garayo "El Sacamantecas". Madrid: El Liberal.

Foucault, M. (2003). Le pouvoir psychiatrique. Cours au Collège de France. 1973-1974. Paris: Gallimard.

Gaceta de Madrid, "Decreto de 3 de julio de 1931 dictando reglas relativas a la asistencia de enfermos psíquicos", n. 188, 7 de julio de 1931, pp. 186-189.

Galán, V. (2009). La recepción extraacadémica de Michel Foucault en la cultura de la transición española: la antipsiquiatría y la historia de la locura en los psiquiatras progresistas. Revista de la Asociación Española de Neuropsiquiatría, 29(104), 485-500.

Goffman, E. (1961). Asylums: Essays on the Social Situation of Mental Patients and Other Inmates, New York: Doubleday Anchor.

González de Chávez, M. (2003). La generación de la democracia. De la coordinadora psiquiátrica a la Asociación Española de Neuropsiquiatría. Frenia, 3(1), 87-114.

González, E. (1977). A siquiatría galega e o siquiátrico de Conxo. Análisis dunha experiencia frustrada. La Coruña: Ed. do Rueiro.

Huertas, R. (1998). Una nueva Inquisición para un Nuevo Estado: Psiquiatría y orden social en la obra de Antonio Vallejo Nágera. In R. Huertas, \& C. Ortiz (Eds.), Ciencia y Fascismo (pp. 98-109). Aranjuez: Doce Calles.

Huertas, R. (2000). Política sanitaria: de la Dictadura de Primo de Rivera a la II ${ }^{\mathrm{a}}$ República. Revista Española de Salud Pública, 74, 37-45.

Huertas, R. (2003). Elaborando doctrina: teoría y retórica en la obra de José María Esquerdo (1842-1912), Frenia, 3(2), 81-109. 


\section{HISTÓRIA DA PSIQUIATRIA}

Huertas, R. (2008). Between doctrine and clinical practice: nosography and semiology in the work of Jean-Etienne-Dominique Esquirol (1772-1840). History of Psychiatry, 19(2), 123-140.

Huertas, R. (2016). El modelo de atención psiquiátrica en el primer franquismo: rupturas y continuidades. In R. Campos, \& A. González de Pablo (Eds.), Psiquiatría e higiene mental en el primer franquismo (pp. 17-45). Madrid: La Catarata.

Huertas, R., \& Novella, E. (2013). Sexo y modernidad en la España de la Segunda República. Los discursos de la ciencia. Arbor, 189(764): a090. doi: http://dx.doi. org/10.3989/arbor.2013.764n6013.

James, F. E. (1992). Insulin treatment in psychiatry. History of psychiatry, 3, 221-235.

Kroeger, B. (1994). Nellie Bly: Daredevil, Reporter, Feminist. New York: Times Books/Random House.

Lera, A. M. (1972). Mi viaje alrededor de la locura. Barcelona: Planeta.

Luna de Tena, T. (1965). Pepa Niebla. Barcelona: Planeta.

Luca de Tena, T. (1993). Franco si, pero... Barcelona: Planeta.

Luca de Tena, T. (2005). Los renglones torcidos de Dios. Barcelona: Planeta. (Edición original de 1979).

Martínez Azumendi, O. (2005). Periodistas y reporteros gráficos como agentes de cambio en psiquiatría. Imágenes-denuncia para el recuerdo. Revista de la Asociación Española de Neuropsiquiatría, 25(96), 9-28.

Mira, A. (2004). De Chueca a Sodoma. Una historia cultural de la homosexualidad en España en el siglo XX. Barcelona-Madrid: Egales.

Mitchell, P. B., \& Kirkby, K. C. (2014). Biological therapies before the introduction of modern psychotropic drugs. In F. López Muñoz, C. Álamo, \& E. Domino (Eds.), History of Psychopharmacology (Vol. 2, pp. 327-347). Arlington: NPP Books.

Polo, C. (1999). Crónica de un manicomio. Prensa, locura y sociedad. Madrid: Asociación Española de Neuropsiquiatría.

Ponce, J. M. (2004). El destape nacional. Crónica del desnudo en la transición. Barcelona: Glenat España.

Quesada, M. A. (1975). La contrarreforma de Conxo. Triunfo, 671, 21.

Rendueles, G. (1997). De la coordinadora psiquiátrica a la Asociación Española de Neuropsiquiatría. In V. Aparicio (Ed.), Orígenes y fundamentos de la psiquiatría española (pp. 287-309). Madrid: Ela-Arán.

Rey, A., \& Martí Boscá, J. V. (2008). En una fábrica de locos... Psiquiatría y prensa obrera en la segunda República Española. In J. Martínez, J. Estévez, M. del Cura, 


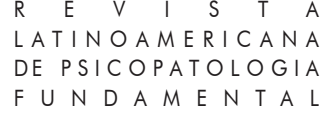

et al. La gestión de la locura: conocimiento, prácticas y escenarios (España, siglos XIX-XX) (pp. 165-196). Cuenca: Universidad de Castilla La Mancha.

Rodríguez Puértolas, J. (2008). Historia de la literatura fascista española II. Madrid: Akal.

Salter, M. (2003). Psychiatry and the media: from pitfalls to possibilities. Psychiatric Bulletin, 27, 123-125.

Salter, M., \& Byrne, P. (2000). The stigma of mental illness: How you can use the media to reduce it. Psychiatric Bulletin, 24, 281-283.

Sérieux, P., \& Capgras, J. (1909). Les folies raisonantes. Les délires d'interpretation. Paris: Félix Alcan.

Shorter, E., \& Healy, D. (2007). Shock Therapy: A History of Electroconvulsive Treatment in Mental Illness. New Brunswick, NJ: Rutgers University Press.

Vallejo-Nágera, J. A. (1985). Yo, el rey. Barcelona: Planeta.

Vallejo-Nágera, J. A. (2005). Prólogo. In T. Luca de Tena. Los renglones torcidos de Dios (p. 9-13). Madrid: Planeta. (Edición original de 1979).

\section{Resumos} Dios)

(Psiquiatria e literatura na Espanha da transição: Los renglones torcidos de

O objetivo deste trabalho é analisar os conteúdos psiquiátricos do romance Los renglones torcidos de Dios [As linhas tortas de Deus] (1979), de Torcuato Luca de Tena, a fim de avaliar de que forma essa obra de ficção foi capaz de espelhar a realidade assistencial na Espanha dos anos $1970 \mathrm{em}$ um contexto de profundas transformações culturais no âmbito da loucura. O romance reflete uma posição conservadora de resistência e critica as novidades (a psicanálise, o movimento antipsiquiátrico) que estavam a propiciar uma nova "cultura psi" na Espanha da transição democrática.

Palavras-chave: Torcuato Luca de Tena, psiquiatria, antipsiquiatria, manicômio, transição espanhola

(Psychiatry and literature in transition-era Spain: Los renglones torcidos de Dios)

This paper analyses the psychiatric content of the novel Los Renglones Torcidos de Dios [The Twisted Lines of God] (1979), by Torcuato Luca de Tena, so as to assess in what way this was capable of reflecting the reality of care in 1970s Spain, 


\section{HISTÓRIA DA PSIQUIATRIA}

within a context of deep cultural changes concerning the concept of madness. The novel reflects a conservative position of resistance and criticizes new developments (psychoanalysis, the anti-psychiatric movement) brought about by a new 'psy culture' in Spain during its transition to democracy.

Keywords: Torcuato Luca de Tena, psychiatry, anti-psychiatry, psychiatric hospital, Spanish Transition

(Psychiatrie et littérature dans l'Espagne de la Transition : Los renglones torcidos de Dios)

L'article qui suit vise à analyser les contenus psychiatriques du roman de Torcuato Luca de Tena Los renglones torcidos de Dios [Les lignes tordues de Dieu] (1979) afin d'analyser de quelle façon cet ouvrage de fiction réussit à rapporter la réalité des services psychiatriques dans l'Espagne des années 1970, dans un contexte de profonds changements culturels dans le domaine de la folie. Le roman dénonce une position conservatrice de résistance et critique par rapport aux nouveautés (la pschanalyse, le mouvement antipsychiatrique) qui encourageaient une nouvelle "culture psy » en Espagne pendant la transition démocratique.

Mots clés: Torcuato Luca de Tena, psychiatrie, antipsychiatrie, asile psychiatrique, transition espagnole

(Psychiatrie und Literatur zur Zeit der spanischen Transition: Los renglones torcidos de Dios)

Das Ziel dieser Arbeit besteht darin, die psychiatrischen Inhalte des 1979 von Torcuato Luca de Tena geschriebenen Romans Los renglones torcidos de Dios (Die schiefen Zeilen Gottes) zu analysieren, um zu beurteilen inwiefern es diesem Roman gelungen ist, die Situation des spanischen Gesundheitswesens in den siebziger Jahren widerzuspiegeln, dass zu dieser Zeit bedeutende kulturelle Veränderungen bezüglich des Wahnsinns erfuhr. Der Roman vertritt eine konservative Widerstandshaltung und kritisiert die Neuerungen (Psychoanalyse, Antipsychiatrie-Bewegung), welche die sogenannte „Psy-Kultur” während der demokratischen Transition in Spanien förderten.

Schlüsselwörter: Torcuato Luca de Tena, Psychiatrie, Antipsychiatrie, psychiatrische Anstalt, spanische Transition

(西班牙民主过渡时期的精神分析学和文学: 《上帝的笔误》 (Los renglones torcidos de Dios)

本文分析了西班牙作家 Torcuato Luca de Tena 的小说《上帝的笔误》 (Los renglones torcidos de Dios) （1979）中的精神分析的描述。该小说在 精神病理念发生深度文化变革的背景之下，如实反映 20 世纪 70 年代西班牙 


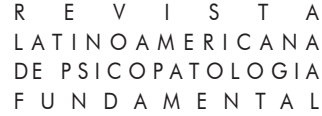

的医疗护理现实。小说以一种保守的立场，抵制和批评民主过渡时期西班牙新 的 “精神分析文化” 带来的新变化（心理分析法、反精神分析运动）。

关键词: Torcuato Luca de Tena, 精神分析学, 反精神分析学, 精神病院, 西班牙民主转型

Citação/Citation: Huertas, R.. (2017, março). Psiquiatría y literatura en la España de la transición: Los renglones torcidos de Dios (1979). Revista Latinoamericana de Psicopatologia Fundamental, 20(1), 142-164.

Editores do artigo/Editors: Profa. Dra. Ana Maria G. Raimundo Oda e Prof. Dr. Paulo Dalgalarrondo.

Recebido/Received: 22.02.2017/ 02.22.2017 Aceito/Accepted: 09.03.2017 / 03.09.2017

Copyright: (C) 2009 Associação Universitária de Pesquisa em Psicopatologia Fundamental/ University Association for Research in Fundamental Psychopathology. Este é um artigo de livre acesso, que permite uso irrestrito, distribuição e reprodução em qualquer meio, desde que o autor e a fonte sejam citados / This is an open-access article, which permits unrestricted use, distribution, and reproduction in any medium, provided the original authors and sources are credited.

Financiamento/Funding: Pesquisa financiada pelo Ministerio de Economia y Competitividad - Mineco de España e o Fondo Europeo de Desarrollo Regional - Feder / The research was funded by the Ministerio de Economia y Competitividad - Mineco de España e o Fondo Europeo de Desarrollo Regional - Feder.

Conflito de interesses/Conflict of interest: $\mathrm{O}$ autor declara que não há conflito de interesses / The author has no conflict of interest to declare.

\section{Rafael Huertas}

Doctor en Medicina por la Universidad Complutense de Madrid (Madrid, España); Profesor de Investigación. Departamento de Historia de la Ciencia. Instituto de Historia-Centro de Ciencias Humanas y Sociales - Consejo Superior de Investigaciones Científicas (CSIC). (Madrid, España).

Centro de Ciencias Humanas y Sociales - CSIC

C/ Albasanz, $26-28$

28037 Madrid, España

rafael.huertas@cchs.csic.es

This is an open-access article, which permits unrestricted use, distribution, and reproduction in any medium for non-commercial purposes provided the original authors and sources are credited. 